\title{
MODIFICATIONS OF ORIGINAL TEXTS OF FAIRY TALES
}

\author{
Natalya V. Petrova \\ Irkutsk State University, Irkutsk, Russian Federation
}

\begin{abstract}
The task of the article is to consider the types of modifications of the original texts of fairy tales leading to the creation of secondary texts. Secondary texts are referred to the intertextuality of the paradigmatic type based on the mechanisms of approximation and modification. Approximation makes the original and the secondary texts recognizable. Modification seeks to change the form and/ or content of the original text. It is associated with creativity, with the introduction of a new meaning in the secondary text of the fairy tale. It is proved that the modifications of two types - travestying and non-travestying - are created on the basis of the original texts of fairy tales. At the present time, we can observe the tendency of refusing the satirical parody in favour of the purely humorous form. It is obvious from the analysis of fairy tales modifications of the travestying type, the humorous effect of which is created as a result of changes in the content of the original text. Modifications of the non-travestying type are aimed at changing the form of the original text of the fairy tale and preserving its content. They do not create a humorous effect and are characterized by pronounced approximation. Common modifications of the non-travestying type are the presentation of prosaic texts of fairy tales in verse form.

Key words: fairy tale, original text, secondary text, modification of travestying type, modification of nontravestying type.

Citation. Petrova N.V. Modifications of Original Texts of Fairy Tales. Vestnik Volgogradskogo gosudarstvennogo universiteta. Seriya 2, Yazykoznanie [Science Journal of Volgograd State University. Linguistics], 2017, vol. 16, no. 3, pp. 207-213. (in Russian). DOI: https://doi.org/10.15688/jvolsu2.2017.3.21

УДК 81 ' $42: 82-343.4$

Дата поступления статьи: 20.02.2017

ББК 81.055

Дата принятия статьи: 14.04.2017
\end{abstract}

\section{ТИПЫ МОДИФИКАЦИЙ ПЕРВИЧНЫХ ТЕКСТОВ СКАЗОК}

\author{
Наталья Васильевна Петрова \\ Иркутский государственный университет, г. Иркутск, Российская Федерация
}

\begin{abstract}
Аннотация. В задачу статьи входит рассмотрение трансформаций первичных текстов сказок (фольклорных и литературных), ведущих к созданию вторичных текстов. Выявлено, что вторичные тексты характеризуются их отнесенностью к интертекстуальности парадигматического типа, основанной на механизмах аппроксимации и модификации. Аппроксимация обеспечивает узнаваемость первичного текста во вторичном тексте. Модификация направлена на изменение формы и / или содержания первичного текста. Она сопряжена с творчеством, с внесением нового смысла во вторичный текст сказки. Установлено, что на основе первичных текстов сказок создаются модификации двух видов: пародирующего и непародирующего типа. На современном временном срезе очевидна тенденция отхода пародии от сатирической в сторону исключительно юмористической формы, что и прослеживается при анализе модификаций сказок пародирующего типа, в которых юмористический эффект создается в результате изменений содержания первичного текста. Модификации непародирующего типа направлены на изменение формы первичного текста сказки и сохранение его содержания. Они не создают юмористического эффекта и характеризуются ярко выраженной аппроксимацией. Распространенными модификациями непародирующего типа являются изложения прозаических текстов ска() зок в стихотворной форме.
\end{abstract}


Ключевые слова: сказка, первичный текст, вторичный текст, модификация пародирующего типа, модификация непародирующего типа.

Цитирование. Петрова Н. В. Типы модификаций первичных текстов сказок // Вестник Волгоградского государственного университета. Серия 2, Языкознание. - 2017. - T. 16, № 3. - C. 207-213. - DOI: https://doi.org/ 10.15688/jvolsu2.2017.3.21

1

Сказка - наиболее древний жанр словотворчества, относящийся к фольклорным произведениям. Термин фольклор произошел от английского folklore, переводимого на русский язык как «народная мудрость». Однако фольклорная сказка не только является отражением народной мудрости, но и порождается самим народом; ее автор - коллективно-обезличенный субъект.

В настоящее время существует множество литературных сказок, в отличие от народных они имеют конкретного автора и несут в себе индивидуально-авторское понимание сказочных сюжетов. По определению Л.Н. Прохоровой, литературная сказка - это сложный жанр, относящийся к письменному дискурсу, который включает совокупность характеристик, входящих как в прототипическую модель жанра фольклорной сказки, так и в структуры других категорий литературного дискурса. Л.Н. Прохорова утверждает, что в литературной сказке возможны отклонения от жесткой схемы народной сказки [Прохорова, 2003, с. 8]. Иными словами, литературная сказка, с одной стороны, сохраняет общие свойства жанра народной сказки, с другой - привносит нечто новое, индивидуальное.

Сказки - это обязательный элемент индивидуального когнитивного пространства человека, которое понимается нами как сумма знаний, хранящихся в памяти человека. Сказки, с детства хорошо знакомые каждому представителю этноса, часто становятся объектами модификаций с целью создания вторичного текста.

Первичный текст сказки может существовать в нескольких вариантах, например, известная русская народная сказка «Лиса и Волк» бытует в двух существенно различающихся вариантах: в первом варианте сказки в отличие от второго появляется ряд деталей. В первом варианте Лиса преднамеренно зо- вет людей, чтобы те расправились с Волком. Во втором варианте все происходит случайно: у проруби, где волк мечется с вмерзшим хвостом, появляется женщина с ведром. В обоих вариантах сказки Волк лишается хвоста, однако в первом варианте сказка этим и завершается, а второй вариант дополняется описанием изощренного обмана, на который пускается Лиса (намазывание тестом головы, тесто вместо мозгов) с тем, чтобы вызвать сочувствие Волка и избежать наказания за свою проделку.

Бытование сказок в нескольких вариантах за счет внесения дополнительных деталей, эмоционального усиления диалогов персонажей, продолжения сказки обусловлено устностью существования сказки и отсутствием конкретного автора. При наличии нескольких вариантов сказки точно установить, какой из них является первоисточником, как правило, не представляется возможным. Поэтому целесообразно говорить о вариантах одной сказки, а не о первичном или вторичном текстах. Понятие вторичного текста будем использовать исключительно для современных переложений текстов сказок, созданных на основе одного из вариантов сказок.

2

Конститутивным свойством вторичных текстов является аппроксимация [Александрова, 2012; Ионова, 2006]. Под аппроксимацией в теории текста понимается приблизительность вторичного текста по отношению к первичному тексту. Аппроксимация обеспечивается сохранением элементов первичного текста (лексических и грамматических единиц, персонажей, пространственновременных координат, сюжетных линий, мотивов) и узнаваемостью первичного текста во вторичном. Связь первичного и вторичного текстов может быть представлена следующим образом: 


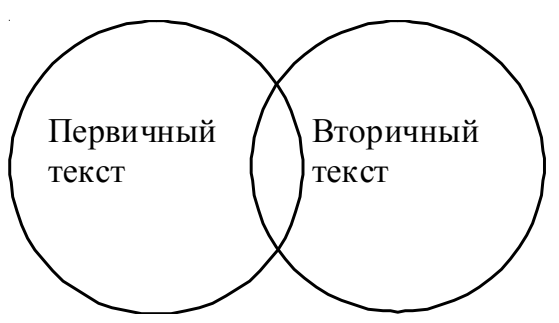

Та часть, которая объединяет пересекающиеся круги, являет собой сохраненные при порождении вторичного текста элементы и свидетельствует о связи первичного и вторичного текстов. Непересекающиеся части содержат элементы, различающие первичный и вторичный тексты. В основе создания различий во вторичном тексте лежит механизм модификации, направленный на изменение первичного текста.

Термины «первичный текст» и «вторичный текст» находят свое место в теории интертекстуальности. Различают интертекстуальность двух видов: 1) интертекстуальность, построенную на основе включения в текст-реципиент частей прототекста или целых прототекстов; 2) интертекстуальность, основанную на имитации и модификации текста-источника с целью получения измененного текста-результата. Вслед за Ю.С. Гавриковой, первый вид интертекстуальности назовем синтагматической интертекстуальностью, а второй - парадигматической интертекстуальностью [Гаврикова, 2012, с. 76].

Существенное различие между данными видами интертекстуальности состоит в том, что синтагматическая интертекстуальность имеет «внутреннюю вторичность», построенную по принципу «текст в тексте» и характеризуемую сменой авторства (таких авторов, как правило, бывает несколько) при включении чужих текстов в текст-реципиент, при этом интегрирующая роль принадлежит автору, имя которого написано на обложке книги. Основными признаками синтагматической интертекстуальности являются цитаты и аллюзии. При парадигматической интертекстуальности обычно взаимодействуют тексты двух авторов: автора первичного текста и автора вторичного текста. В результате создается новый самостоятельный текст, где автором является продуцент вторичного текста [Гаврикова, 2012, с. 76].
Далее будем придерживаться определения вторичных текстов как текстов, относящихся к явлениям парадигматической интертекстуальности, образованных путем модификации первичного текста.

\section{3}

Чаще других модификациям подвергаются народные сказки с коллективно-обезличенным субъектом, в которых при создании вторичного текста авторство переходит, как правило, к конкретному лицу.

Различаются модификации двух видов: модификации пародирующего характера и модификации непародирующего характера.

3.1. Чтобы раскрыть суть модификаций пародирующего типа следует обратиться к понятию пародии. Приведем несколько его определений, принятых в научной, учебной и справочной литературе. Пародия - поэтическое или прозаическое произведение или жанр, основанный на комическом воспроизведении поэтики и стиля какого-нибудь писателя или отдельного текста [Арнольд, 1999, с. 307]. Пародия (от греч. parodia - противоnеснь) - вид сатирического произведения, целью которого служит осмеяние литературного направления, жанра, стиля, манеры писателя, отдельного произведения [Тимофеев, 1974, с. 259]. Пародия - подражание, утрированно повторяющее особенности оригинала, выражающие насмешливо-критическое отношение к некоторым героям, идеям, стилистическим особенностям источника при некотором его почитании и даже восхищении его качествами [Борев, 2003, с. 289]. Пародии - это перелицовки предшествующих литературных фактов, будь то отдельные произведения или «типовые» явления писательского творчества (жанры, стилевые установки, укорененные художественные приемы) [Хализев, 2000, с. 250-251]. Пародия - специфическое использование различных языковых средств с целью комического подражания стилю какого-либо писателя или литературного направления [Ахманова, 2007, с. 313].

В существующих определениях четко прослеживается связь пародии с первичным текстом, благодаря которой обеспечивается узнаваемость текста-источника. На эту осо- 


\section{МАТЕРИАЛЫ И СООБЩЕНИЯ}

бенность пародии особое внимание обращает И.В. Арнольд, отмечая, что направленность на какое-нибудь известное читателям произведение или ряд произведений или направление и упор на эту соотнесенность является характерным признаком пародии [Арнольд, 1999, с. 307]. Обновление произведения за счет внесения различного рода изменений составляет другую важную особенность пародий как вторичных текстов. Пародия, таким образом, представляет собой «парадигму подражания и трансформации произведений» [Пьеге-Гро, 2008, с. 64].

Возвращаясь к приведенным ранее определениям пародии, обратим внимание на то, что в одних определениях особо подчеркивается наличие у пародий сатирической формы, в других - юмористической формы. Известно, что существуют пародии двух видов: юмористическая и сатирическая. Юмористическая пародия является комическим подражанием оригиналу, доброжелательная и дружеская по отношению к пародируемому автору. Сатирическая пародия противостоит оригиналу, высмеивает и отрицает идейную и эстетическую сущность произведения, автора или литературного направления [Тимофеев, 1974, с. 259].

Отметим, что установка пародий на сатиричность существовала в советское время. Так, в «Литературной энциклопедии», вышедшей в одиннадцати томах в период с 1929 по 1939 г., пародия определяется как «вид литературной сатиры, сатира на литературный стиль, при помощи которой ведется нападение на классово враждебную идеологию. <..> Она разоблачает враждебный класс, компрометируя его литературу, всю его стилевую систему, или исправляет и очищает литературу своего класса от чуждых влияний или пережитков» [Литературная энциклопедия].

В социалистическом обществе пародия рассматривалась как важное идеологическое оружие. В те времена имела место и пародия, «направленная на отдельные мелкие и более "невинные" недочеты своей литературы». Она была более мягкой и квалифицировалась как пародия юмористическая, цель которой - «эстетское развлекательство» [Литературная энциклопедия].
На современном этапе развития общества пародия уже не играет такую «боевую, активную роль в классовой борьбе на литературном фронте» [Литературная энциклопедия], а скорее служит средством развлечения, при этом юмористичность пародии выступает на первый план. Таким образом, из двух видов пародий (сатирической и юмористической) широкое распространение получает юмористическая пародия, основным средством создания которой является невраждебное ироническое подражание осмеиваемому образцу. Следовательно, юмористичность - это еще одно важное свойство современной пародии.

Модификации пародирующего типа как вторичные тексты юмористического характера создаются на основе первичного текста при участии двух основных механизмов: сохранения и трансформации.

Модификации пародирующего характера являются самым распространенным способом создания вторичных текстов сказок.

Приведем пример:

Была узайца избушка лубяная, а у лисы - коттедж на Мальдивах. Пришла как-то лиса к зайцу, да и говорит: «Давай, зайка меняться - ты мне избушку лубяную, а я тебе коттедж на Мальдивах. Посмотрел заяц на лису... и понял... рехнулась лиса... (Ву).

В известной сказке о Лисе и Зайце, послужившей источником создания приведенного выше вторичного текста, повествуется о том, что у Лисы была избушка ледяная, а у Зайца - лубяная. С наступлением весны ледяная избушка Лисы растаяла. Воспользовавшись своей силой, Лиса выгнала Зайца из его лубяной избушки.

Вторичная сказка носит пародирующий характер. Она противопоставлена первичному тексту: у Лисы более престижная «жилплощадь»-квартира на известном курорте. Во вторичной сказке резко меняется и поведение Лисы. Она вдруг предлагает Зайцу свою квартиру для обмена на его лубяную избушку. Внесенные во вторичный текст изменения способствуют созданию юмористического эффекта, эксплицитно выраженного в реакции Зайца на предложение Лисы (Посмотрел заяи на лису... и понял... рехнулась лиса...).

Рассмотрим пример модификации пародирующего типа при создании вторичного тек- 
ста на основе сказки «Золушка». Во вторичном тексте сказочное действие перенесено в Москву в наше время. Все персонажи во вторичном тексте сохранены за исключением короля и принца. Вместо короля во вторичном тексте действует олигарх, а вместо принца сын олигарха:

\author{
Жил от них неподалеку \\ Олигарх не по намеку. \\ Сам по имени Тигран, \\ По фамилии Абрамян. \\ Был сыночек у него, \\ Крут, не скажешь ничего, \\ Смесь евреев и армян, \\ Звали Гарик Абрамян. (Семисолнцева)
}

Слово олигарх вызывает ассоциации с крупным бизнесменом, капитал которого позволяет ему оказывать решающее влияние на формирование и принятие решений в своих личных и групповых интересах со стороны государства. Модификация на уровне персонажей привносит во вторичный текст элемент современности. Фамилия Абрамян имеет явный намек на известного олигарха Романа Абрамовича (Абрам-ян - Абрам-ович). Во вторичном тексте осмеянию подвергаются современные золушки, для которых важны не личностные качества жениха, а наличие у него богатенького папочки и денег.

3.2. Модификации непародирующего типа, в отличие от модификаций пародирующего типа, не носят юмористического характера. При таких модификациях общее содержание первичного текста сказки сохраняется, изменяется только форма. Примером модификации непародирующего типа может служить переложение сказки «Репка» в стихотворную форму:

\footnotetext{
PEПКА

Старик семя посадил,

Лето целое поил.

Репка выросла большой

И с кудрявою ботвой.

Потянул старик тот плод -

Из земли он не идет.

Дед позвал на помощь бабку,

Крепче взял ботву в охапку.

Бабка деда потянула,

Сколько было сил, рванула.

Репка даже не качнулась,
}

Лишь листва ее встряхнулась. Бабка внучку кликать стала, Та немедля прибежала. За бабку взяться поспешила, Старуха деда обхватила.

Дед за стебли крепче взял

И тянуть команду дал.

Со всей силы все старались

Ногами в землю упирались.

Только репка ни на пядь

Не желала вылезать.

Внучка Жучку покричала,

Та на помощь прибежала,

За ее полу вцепилась,

За бабку внучка ухватилась.

За деда бабушка взялась,

В его руках ботва сплелась.

Вновь старанье применили,

Дружно плод с гряды тащили.

Но он с землей корнями слился

И выходить не торопился.

Жучка кошку попросила:

«Помоги, нужна нам сила,

Репку с грядки удалить

Чтоб семью ей накормить».

На помощь кошка прибежала

И в единой цепи встала.

Друг за друга потянули,

Всю ботву в дугу согнули.

Репка спелая качалась,

А от земли не отрывалась.

Позвала тут кошка мышку,

Длиннохвостую малышку:

«Приходи нам помогать

Репку с грядочки сорвать».

Мышка репку осмотрела,

Кошке хвост подать велела,

Крепенько его взяла,

В ожиданье замерла.

По команде потянули,

Поднатужившись, рванули.

Репка вышла из земли,

Ее тут же в дом внесли.

В той избе и я бывал,

Репку славную видал.

Ее размером поражался,

Прекрасным вкусом наслаждался. (Иванов, с. 3)

Во вторичном тексте полностью сохранены действующие лица и сюжет первичной сказки о репке. Внесенные во вторичный текст детализирующие элементы продиктованы необходимостью «втиснуть» содержание первичного текста сказки в стихотворную форму при сохранении сути первичной сказки. Пародирующие элементы во вторичной сказке отсутству- 
ют. Единственная цель ее автора - использовать известный сюжет, по-видимому, для тренировки в создании стихотворной формы.

\section{4}

Итак, модификации первичных текстов сказок с целью создания вторичных текстов сказок основаны на механизмах аппроксимации, обеспечивающей узнаваемость первичного текста во вторичном, и изменений, связанных с внесением нового содержания или новой формы во вторичный текст. Модификации пародирующего характера наиболее распространены в литературной практике, они направлены на создание юмористического эффекта путем изменения содержания первичного текста сказки. Основная цель таких текстов - высмеять недостатки современного общества и развлечь читателя. Для модификации непародирующего характера свойственны изменения формы первичного текста сказки. Если в модификациях пародирующего характера происходит обновление содержания первичного текста, то в модификациях непародирующего характера - обновление формы первичного текста сказки.

\section{СПИСОК ЛИТЕРАТУРЫ}

Александрова, А. А. Реализация категория аппроксимации в тексте пародии / А. А. Александрова // Известия Российского государственного педагогического университета им. А.И. Герцена. 2012. - № 153-1. - С. 38-44.

Арнольд, И. В. Семантика. Стилистика. Интертекстуальность / И. В. Арнольд. - СПб. : СПбГУ, 1999. - 444 c.

Ахманова, О. С. Словарь лингвистических терминов / О. С. Ахманова. - М. : КомКнига, 2007. $576 \mathrm{c}$.

Борев, Ю. Б. Эстетика. Теория литературы: Энциклопедический словарь терминов / Ю. Б. Борев. - М. : Астрель, АСТ, 2003. -575 с.

Гаврикова, Ю. С. Интертекстуальность англоязычных антиутопий : дис. ... канд. филол. наук / Гаврикова Юлия Сергеевна. - Воронеж, 2012. $243 \mathrm{c}$.

Ионова, С. В. Аппроксимация содержания вторичных текстов / С. В. Ионова. - Волгоград : Издво ВолГУ, 2006. -380 с.

Литературная энциклопедия. - Электрон. текстовые дан. - Режим доступа: http://slovarionline.ru/ literaturnaya_entsiklopediya/page/parodiya.4223 (дата обращения: 14.11. 2016). - Загл. с экрана.

Прохорова, Л. П. Интертекстуальность в жанре литературной сказки (на материале английских литературных сказок) : автореф. дис. ... канд. филол. наук / Прохорова Лариса Петровна. - Иркутск, 2003. $-18 \mathrm{c}$.

Пьеге-Гро, Н. Введение в теорию интертекстуальности / Н. Пьеге-Гро. - М. : Изд-во ЛКИ, 2008. $-240 \mathrm{c}$.

Тимофеев, Л. И. Словарь литературоведческих терминов / Л. И. Тимофеев, С. В. Тураев. - М. : Просвещение, 1974. - 509 с.

Хализев, В. Е. Теория литературы / В. Е. Хализев. - М. : Высшая школа, 2000. - 398 с.

\section{ИСТОЧНИКИ}

By - Ву, Д. Пародии на сказки несказочной развязки / Д. Ву. - Электрон. текстовые дан. - Режим доступа: http://my-works.org (дата обращения: 05.07.2016). - Загл. с экрана.

Иванов - Иванов, Ю. Т. Русские народные сказки в стихах : в 2 кн. / Ю. Т. Иванов. - Иркутск : Форвард, 2011. - Кн. 1. - 44 с.

Семисолнцева - Семисолнцева, В. Золушка / В. Семисолнцева. - Электрон. текстовые дан. Режим доступа: http://www/stihi.ru/ avtor/intro999 (дата обращения: 15.12.2015). - Загл. с экрана.

\section{REFERENCES}

Aleksandrova A.A. Realizatsiya kategoriya approksimatsii $v$ tekste parodii [The Implementation of the Category of Approximation in the Parody Text]. Izvestiya Rossiyskogo gosudarstvennogo pedagogicheskogo universiteta im. A.I. Gertsena [Izvestia: Herzen University Journal of Humanities and Sciences], 2012, no. 153-1, pp. 38-45.

Arnold I.V. Semantika. Stilistika. Intertekstualnost [Semantics. Stylistics. Intertextuality]. Saint Petersburg, Izd-vo St. Petersburg. un-ta, 1999. 444 p.

Akhmanova O.S. Slovar lingvistitseskikh terminov [The Dictionary of Linguistic Terms]. Moscow, KomKniga Publ., 2007. 576 p.

Borev Yu.B. Estetika. Teoriya literatury: Entsiklopedicheskiy slovar terminov [Aesthetics. Theory of Literature: Encyclopedic Dictionary of Terms]. Moscow, Astrel, AST Publ., 2003. 575 p.

Gavrikova Yu.S. Intertekstualnost angloyazychnyk antiutopiy: dis. ... kand. filol. nauk [Intertextuality in EnglishAnti-utopia. Cand. philol. sci. diss.]. Voronezh, 2012. 240 p. 
Ionova S.V. Approksimatsiya soderzhaniya vtorichnykh tekstov [The Approximation of the Content of Secondary Texts]. Volgograd, Izd-vo VolGU, $2006.380 \mathrm{p}$.

Literaturnaya entsiklopediya [Encyclopedia of Literature]. URL: http://slovarionline.ru/literaturnaya entsiklopediya/page/parodiya.4223. (accessed November 14, 2016).

Prokhorova L.P. Intertekstualnost $v$ zhanre literaturnoy skazki (na materiale angliyskikh literaturnykh skazok): avtoref. dis. ... kand. filol. nauk [Intertextuality in the Genre of Literary Fairy Tales (Case Study of English Literary Fairy Tales). Cand. philol. sci. abs. diss.]. Irkutsk, 2003. 18 p.

Pyege-Gro N. Vvedenie $v$ teoriyu intertekstualnosti [Introduction to the Theory of Intertextuality]. Moscow, Izd-vo LKI, 2008. 240 p.

Timofeev L.I., Turaev S.V. Slovar literaturovedcheskikh terminov [The Dictionary of
Literary Terms]. Moscow, Prosveshchenie Publ., 1974. 509 p.

Khalizev V.E. Teoriya literatury [The Theory of Literature]. Moscow, Vysshaya Shkola Publ., 2000. $398 \mathrm{p}$.

\section{SOURCES}

$\mathrm{Vu}$ D. Parodii na skazki neskazochnoy razvyazki [Parodies of Tales of the Non-Fairy-Tale Outcome]. URL: http://my-works.org. (accessed July $5,2016)$.

Ivanov Yu.T. Russkie narodnye skazki $v$ stikhakh: v $2 \mathrm{kn}$. [Russian Folk Tales in Verses: In 2 Books]. Irkutsk, Forvard Publ., 2011, Book 1. $44 \mathrm{p}$.

Semisolntseva V. Zolushka [Cinderella]. URL: http://www/stihi.ru/ avtor/intro999. (accessed December 15, 2015).

\section{Information about the Author}

Natalya V. Petrova, Doctor of Sciences (Philology), Professor, Department of Foreign Languages, Irkutsk State University, Karla Marksa St., 1, 664003 Irkutsk, Russian Federation, nvic2004@mail.ru, http://orcid.org/00000-0001-5731-1094

\section{Информация об авторе}

Наталья Васильевна Петрова, доктор филологических наук, профессор кафедры иностранных языков, Иркутский государственный университет, ул. Карла Маркса, 1, 664003 г. Иркутск, Российская Федерация, nvic2004@mail.ru, http://orcid.org/00000-0001-5731-1094 